\title{
A dose-escalating phase I of imatinib mesylate with fixed dose of metronomic cyclophosphamide in targeted solid tumours
}

\author{
A Adenis $^{1,2}$, I Ray-Coquard ${ }^{3,4}$, A Italiano ${ }^{5}$, E Chauzit $^{6}$, B Bui-Nguyen ${ }^{5}$, J-Y Blay ${ }^{3}$, E Tresch-Bruneel $^{7}$, \\ C Fournier ${ }^{7,8}$, S Clisant ${ }^{9}$, E Y Amela ${ }^{1}$, P A Cassier ${ }^{3}$, M Molimard ${ }^{6}$ and N Penel ${ }^{\star, 1,8}$ \\ ${ }^{1}$ Department of Medical Oncology, Centre Oscar Lambret, 3, rue F Combemale, Lille, France; ${ }^{2}$ Catholic University of Lille, Medical \\ School, Lille, France; ${ }^{3}$ Department of Medical Oncology, Centre Léon Bérard, Lyon, France; ${ }^{4}$ Claude Bernard Lyon I University, \\ EAM 4128 Research Unit, Lyon, France; ${ }^{5}$ Department of Medical Oncology, Institut Bergonie, Bordeaux, France; ${ }^{6}$ Pharmaco- \\ Toxicology Laboratory, Bordeaux University Hospital, Victor Segalen University, Bordeaux, France; ${ }^{7}$ Biostastistic and Methodology \\ Unit, Centre Oscar Lambret, Lille, France; ${ }^{8}$ Lille-Nord-de-France Univestity, Medical School, EA2694 Research Unit, Lille, \\ France and ${ }^{9}$ Clinical Research Unit, Centre Oscar Lambret, Lille, France
}

Background: Preclinical findings suggest that imatinib mesylate (IM) and metronomic cyclophosphamide (MC) combination provides synergistic antiangiogenic activity on both pericytes and endothelial cells.

Methods: We have designed a $3+3$ dose-escalating phase I trial with a fixed dose of MC (50 mg two times daily) plus IM ( $400 \mathrm{mg}$ per day; 300 and $400 \mathrm{mg}$ two times daily). Enrolled patients had IM- and sutininib-refractory advanced gastrointestinal stromal tumours (GIST) $(n=17)$, chordoma $(n=7)$ and mucosal melanoma $(n=2)$. Dose-limiting toxicities were monitored for the first 6 weeks. Progression-free survival (PFS) and response assessment are based on RECIST 1.0 guidelines. Pharmacokinetics of IM were measured before and after exposure to MC.

Results: No dose-limiting toxicity was observed. Fourteen patients of the expanded cohort received $400 \mathrm{mg}$ two times daily of IM with MC. Apart from a case of possibly related acute leukaemia occurring after 4 years of treatment, we did not see unexpected toxicity. No drug-drug pharmacokinetic interaction was observed. There was no objective response. We have observed long-lasting stable disease in chordoma patients (median PFS = 10.2 months; range, 4.2-18+) and short-term stable disease in heavily GIST pretreated patients (median PFS $=2.3$ months; range, 2.1-6.6).

Conclusion: This combination is feasible and may warrant further exploration in refractory GIST or chordoma patients.

Metronomic chemotherapy refers to the frequent, usually daily, administration of cytotoxic drugs at doses that are significantly less than the maximum-tolerated dose, with no prolonged drug-free breaks. Oral cyclophosphamide-based metronomic chemotherapy is the most largely studied metronomic regimen with more than 30 retrospective studies and phase II trials reporting in vivo antiangiogenic and immunomodulatory properties and significant clinical antitumour activity, which has been confirmed in heavily treated patients that have exhausted all effective treatments (Penel et al, 2010, 2012).

Imatinib mesylate (IM) is a potent inhibitor of KIT, 'break-point cluster region'-'Abelson' (BCR-ABL), platelet-derived growth factor (PDGFR) and colony-stimulating factor 1 receptor (CSF1R) activities that has marked antitumour activity on chronic myelogenous leukaemia and several other haematological malignancies and solid tumours including gastrointestinal stromal

${ }^{*}$ Correspondence: Dr N Penel; E-mail: n-penel@o-lambret.fr

Presented in part at the 35th ESMO Congress, 8-10 October 2010, Milan, Italy.

Received 12 June 2013; revised 10 September 2013; accepted 16 September 2013; published online 22 October 2013

(c) 2013 Cancer Research UK. All rights reserved 0007-0920/13 
tumours (GISTs) (Blay et al, 2007), chordoma (Stacchiotti et al, 2012), aggressive fibromatosis (Penel et al, 2011a) and melanoma harbouring KIT mutation (Guo et al, 2011), as well as thymic carcinoma with KIT mutations (Schirovi et al, 2012).

Pietras and Hanahan (2005) described the synergistic activity of the combination of metronomic cyclophosphamide (MC) and IM in patient-derived tumour xenograft mouse models. Their study showed that this combination acts as an antiangiogentic treatment, as imatinib interferes with pericyte activity through the inhibition of the PDGFR and oral MC induces the endothelial cell apoptosis. This combination provides an objective response and survival advantage in this mouse model. Until now, the precise antitumour activity of this combination had not precisely determined in humans despite these promising preclinical findings.

In this context, a multi $\backslash \mathrm{e}$ dose-escalating phase I trial to determine the phase II recommended dose of this combination, to determine the impact of oral MC on the IM pharmacokinetic (PK) and to seek some signs of activity in patients with IM and sunitinib-refractory GIST, with chordoma, life-threatening aggressive fibromatosis or melanoma harbouring KIT mutation was conducted.

\section{MATERIALS AND METHODS}

Study design. This is a $3+3$ dose-escalation study, the primary objective of which is to determine the maximum-tolerated dose of a combination of IM associated with fixed dose of oral MC. The eligibility criteria are listed in Table 1 . Tumour response was assessed by RECIST 1.0 every 8 weeks (Therasse et al, 2000).
Dose-escalating process and definition of the maximumtolerated dose. Eligible patients received dose-escalated IM (three dose levels: $400 \mathrm{mg}$ daily, $300 \mathrm{mg}$ two times daily, $400 \mathrm{mg}$ two times daily) for 15 days (until steady state) followed by continuous $50 \mathrm{mg}$ day of MC associated with IM. The choice of MC dose was based on widespread evidence of the long-term tolerability of this schedule (Blay et al, 2007; Penel et al, 2011a). The dose levels of IM have been chosen because of the well-established long-term tolerability of this drug.

Dose-limiting toxicities (DLTs) were assessed during the first 6 weeks of treatment and included an interruption of treatment for more than 4 consecutive days during the first 6 weeks, and the following toxic events (NCI-CTCAE version 3): prolonged ( $>7$ days) grade 4 neutropenia, febrile neutropenia, grade 4 thrombopenia, haemorragia related to thrombopenia, grade 3-4 diarrhoea, grade 3-4 rash as well as any kind of unexpected life-threatening toxicities.

We planned an expanded cohort of 14 additional patients at the phase II recommended dose to better explore the tolerability and the activity of this combination (Penel et al, 2011b).

Pharmacokinetic analyses. Pharmacokinetic analyses were carried out by EC and MM at the Pharmaco-Toxicology Laboratory (University Hospital, Bordeaux, France). Samples had been collected at day 15 (IM alone) and at day 28 (IM + MC). Pharmacokinetic analyses were scheduled before (until steady state) and during the combination at $T_{0}$ (predose), $30 \mathrm{~min}, 1 \mathrm{~h}, 2 \mathrm{~h}$, $3 \mathrm{~h}, 4 \mathrm{~h}, 6 \mathrm{~h}, 10 \mathrm{~h}, 11 \mathrm{~h}, 12 \mathrm{~h}$ (day 1) and $24 \mathrm{~h}$. Metronomic cyclophosphamide and IM were quantified in the serum by liquid chromatography-tandem mass spectrometry methods validated according to Federal Drug Agency guidelines. The mass

\section{Table 1. Eligibility criteria}

\section{Inclusion criteria}

(A) Following cancers: imatinib- and sunitinib-refractory gastrointestinal stromal tumours,

chordoma, dermatofibrosarcoma (locally advanced and progressive), metastatic KIT mutation

harbouring melanoma, metastatic and progressive cylindroma whatever the primary site, desmoid

tumour (life-threatening locations such as progressive mesenteric location or progressive

nasocranial location)

(B) Metastatic disease or locally advanced disease not amenable to curative intent surgery

(C) Disease incurable with standard therapy

(D) Measurable disease according to RECIST (1.0)

(E) No more than two previous lines of systemic anticancer treatments ( 4 weeks since the last dose)

(F) Four weeks since local therapy (major surgery and last fraction of radiation therapy). Patients

must have recovered from toxicity

(G) Age $\geqslant 18$ years

(H) $P S \leqslant(E C O G) 2$ within the 7 days before the study

(I) Albuminaemia $\geqslant 36 \mathrm{gl}^{-1}$ and lymphocytes count $>700 \mathrm{~mm}^{-3}$

(J) Absolute granulocytes $\geqslant 1500 \mathrm{~mm}^{-3}$

(K) Platelets $\geqslant 100000 \mathrm{~mm}^{-3}$

(L) Total bilirubin within normal limits

(M) Serum creatinine within normal limits

(N) Normal left ventricular ejection fraction (by MUGA scan or echocardiogram or NT-proBNP dosage)

(O) Negative pregnancy test within the 7 days before the study

(P) Using effective contraceptive measures

(Q) Absence of any psychological, familial, sociological or geographical condition potentially

hampering compliance with the study protocol and follow-up schedule; those conditions should be

discussed with the patient before registration in the trial

(R) Before patient registration, written informed consent must be given according to ICH/GCP and national regulations

Abbreviations: $E C O G=$ Eastern Cooperative Oncology Group; ICH/GCP =International Conference on Harmonisation/Good Clinical Practice; IM =imatinib mesylate; MUGA = multigated acquisition; NT-proBNP $=\mathrm{N}$-terminal probrain natriuretic peptide; $\mathrm{PK}=$ harmacokinetic; RECIST $=$ Response Evaluation Criteria In Solid Tumours.

\section{Exclusion criteria}

(A) Patients undergoing simultaneous therapy with other anticancer agents

(B) Patients with any prior allergy to cyclophosphamide or IM

(C) Patients with concurrent illness such a congestive heart failure, active serious infection, etc.

(D) Patients not able to stop during the first 2 weeks of treatment

(PK phase) any medication that may interfere with PK of either treatments

(E) Patients not able to swallow and absorb the oral investigational agents 
spectrometer was operated in electrospray ionisation mode with multiple reaction monitoring. Samples $(300 \mu \mathrm{l})$ were prepared by SPE using an MCX Oasis microelution plate (Waters Corporation, Milford, MA, USA), after the addition of an acidic solution ( $\mathrm{pH} 3$ ) containing Internal Standard. The same solid-phase extraction procedure was applied for both methods, but samples were then analysed on different systems: IM was quantified using ultraperformance liquid chromatography coupled with a tandem quadrupole detector (Waters), whereas MC samples were analysed on an Alliance 2695 coupled with Quattro Micro (Waters) (Bouchet et al, 2011).

Ethical considerations. This study was approved by the regional Ethics Committee ('Comite de Protection des Patients Nord-Ouest III', date of approval: 29 May 2009) and by the French Health Products Safety Agency ('Agence Française de Sécurité Sanitaire et des Produits de Santé, 1 June 2009). This study was registered in the European Clinical Trials Register (EudraCT No. 2008-00421212). Informed consent was obtained from each patient.

\section{RESULTS}

Description of the population. Twenty-six patients were included between February 2009 and January 2011. During the doseescalation phase, five patients (the first two patients had been replaced because they were not assessable for the PK analysis) have been enrolled at first dose level (IM $400 \mathrm{mg}$ per day), three patients at second dose level (IM $300 \mathrm{mg}$ two times daily) and four patients at the third dose level (IM $800 \mathrm{mg}$ per day). One of the patients enrolled in the third dose level was never treated (died at day 13 days of biguanide overdose). Fourteen additional patients were enrolled in the expanded cohort (IM $800 \mathrm{mg}$ per day). The study population consisted of 20 men (77\%) and six women (23\%). The median age was 60.5 (range, 41-80) years. The primaries were GIST $(17,65 \%)$, sacral chordoma $(7,27 \%)$ and mucosal melanoma (2, 8\%). The primary locations of GIST were as follows: small intestine (9), stomach (5), rectum (2) and mesenteric (1). Twenty patients $(77 \%)$ had metastatic disease, mainly involving the liver (16 patients), lung (11 patients) or peritoneum (8 patients). At study entry, the performance status (PS) was as follows: $\mathrm{PS}=0$ in 11 patients $(42 \%), \mathrm{PS}=1$ in 14 patients $(54 \%)$ and $\mathrm{PS}=2$ in 1 patient $(4 \%)$. The previous treatments were surgery in 17 cases (65\%), radiotherapy in 5 cases (19\%) and previous molecular targeted therapies in 19 cases $(73 \%)$. One of the two patients with mucosal melanoma had received previous chemotherapy with dacarbazine. Two of the seven patients with chordoma had received previous treatment with IM alone. All patients with GIST have previously been treated with IM alone and suntinib and had progressed. The other treatments administered to patients with GIST were as follows: sorafenib (11 patients), nilotinib (6 patients), $\mathrm{IM}+$ nilotinib (2 patients), masatinib (2 patients) and motesanib (1 patient). All patients experienced progressive disease at study entry.

Dose escalation. No DLT was observed during the dose-escalation phase: the third dose level was retained as the recommended dose for further phase II trial: MC $50 \mathrm{mg}$ two times daily plus IM $800 \mathrm{mg}$ per day.

Tolerance. One patient enrolled in the expanded cohort was not assessable for safety (died at day 13 of biguanide overdose). The safety profile is detailed in Table 2 . Treatment had been suspended for toxicity reason in seven cases (6 out of 14 patients treated at the phase II recommended dose). Doses were reduced for 4 out of 14 patients treated at the phase II recommended dose. One case of acute myeloid leukaemia in a chordoma patient treated with this association for 4 years, thus, a causal relationship is possible.

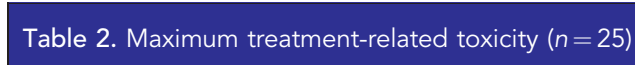

Toxicities observed during the trial participation

\begin{tabular}{|l|c|c|}
\hline Toxicity & $\begin{array}{c}\text { Grade 3 } \\
\text { No. (\%) }\end{array}$ & $\begin{array}{c}\text { Grade 4 } \\
\text { No. (\%) }\end{array}$ \\
\hline Anaemia & $3(12)$ & 0 \\
\hline Neutropenia & $1(4)$ & 2 (8) \\
\hline Lymphopenia & $1(4)$ & $1(4)$ \\
\hline Thrombopenia & $1(4)$ & 0 \\
\hline Fatigue & $3(12)$ & 0 \\
\hline Anorexia & $1(4)$ & 0 \\
\hline Nausea/vomiting & $4(16)$ & 0 \\
\hline Haematuria & $1(4)$ & 0 \\
\hline Proteinuria & $1(4)$ & 0 \\
\hline Rash/skin toxicity & $2(8)$ & 0 \\
\hline Headache & $1(4)$ & 0 \\
\hline Heart failure & 0 & $1(4)$ \\
\hline Secondary malignancy (acute leukaemia) & 0 & $1(4)$ \\
\hline
\end{tabular}

Toxicity observed during the $\mathbf{4 2}$ first days

\begin{tabular}{|l|c|c|}
\hline Anaemia & $1(4)$ & 0 \\
\hline Fatigue & $2(8)$ & 0 \\
\hline Anorexia & $1(4)$ & 0 \\
\hline Nausea/vomiting & $2(8)$ & 0 \\
\hline Rash/skin toxicity & $2(8)$ & 0 \\
\hline Headache & $1(4)$ & 0 \\
\hline Heart failure & 0 & $1(4)$ \\
\hline
\end{tabular}

National Cancer Institute Common Toxicity Criteria( NCl-CT) version 4 grade 3-4 adverse events in all patients: incidence of maximal toxicity considered by investigator as possibly, probably or definitely related to study drugs. One patient died on day 11 of intercurrent cause (biguanide overdose), and was therefore not assessable for safety.

Antitumour activity. Twenty-five patients were assessable for activity. No objective response was observed during the study. The median progression-free survival (PFS) was 3.4 months (95\% CI: 2.5-9) and the median overall survival (OS) was 13.4 months (95\% CI: $3.0-16.0+$ ) in the entire study population. These figures varied widely according to the tumour types. Imatinib mesylate/suntinib GIST patients experienced a PFS of 2.9 months (95\% CI: 2.3-7.6) and an OS of 11.0 months (95\% CI: 3.0-16.0). Chordoma patients experienced long-lasting stable disease, whereas all had progressive disease at study entry. The median PFS and median OS were not reached for chordoma patients. The PFS and OS of mucosal melanoma patients were 2.9 and 5.2 months, respectively (see Figures 1 and 2).

Pharmacokinetic. The area under the curve for IM correlated to the administered dose (Figure 3). Metronomic cyclophosphamide does not modify the PK parameters of IM (Table 3 ).

\section{DISCUSSION}

The key findings of this dose-escalating phase I trial were: (i) the phase II recommended dose is MC $50 \mathrm{mg}$ two times daily plus IM $800 \mathrm{mg}$ per day, (ii) this schedule is well tolerated, (iii) MC does not interfere with the IM PK and (iv) tumour growth arrest was 


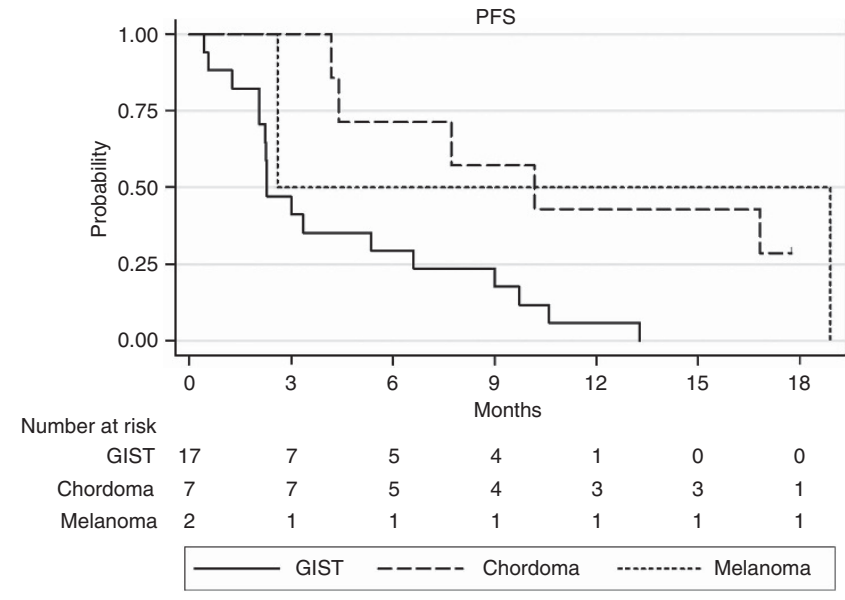

Figure 1. Progression-free survivals by tumour types.

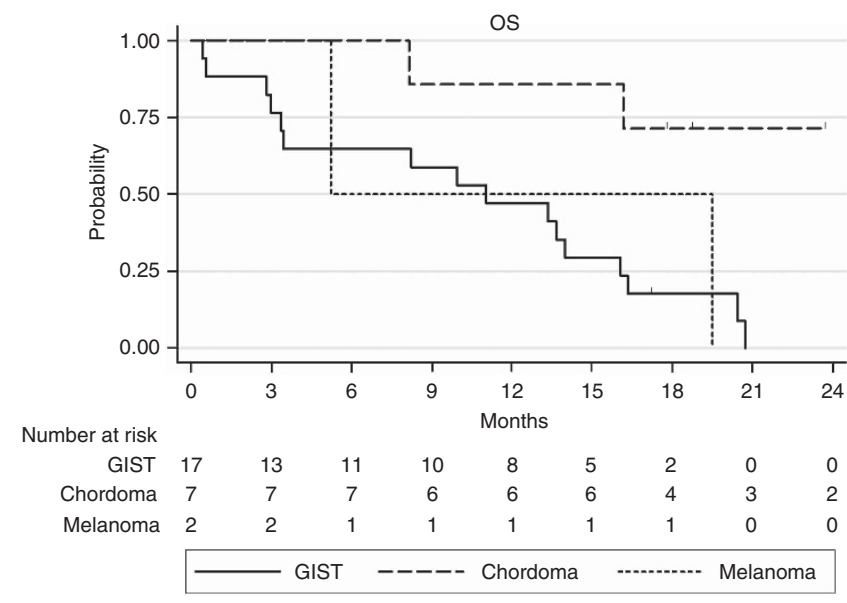

Figure 2. Overall survivals by tumour types.

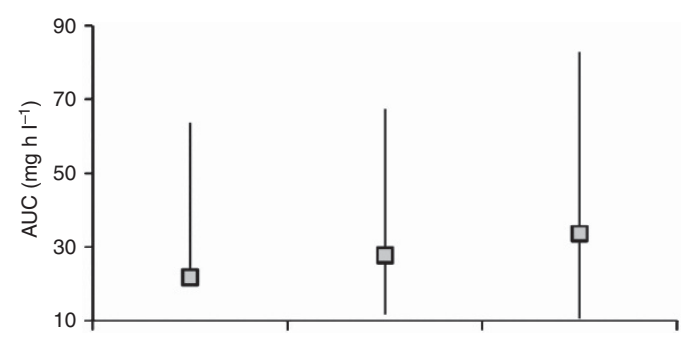

Figure 3. Area under curve (AUC) of imatinib according to the three dose levels: $400 \mathrm{mg}$ daily, $300 \mathrm{mg}$ two times daily, $800 \mathrm{mg}$ daily).

observed in patients with imatinib/sunitib-refractory GIST and chordoma, requiring further clinical investigations.

The tolerance of the combination was mostly manageable without unexpected toxicity. Arterial hypertension and renal toxicity (proteinuria/microscopic haematuria) were only observed in one case. The case of acute leukaemia is possibly related to this combination; cyclophosphamide is a well-established carcinogen (Xu et al, 2013). This patient with a massive sacral chordoma was one of the first enrolled patients and received $400 \mathrm{mg}$ per day of IM plus MC after failure of IM alone. This combination provided pain relief and alleviated nerve palsies. After 18 months of treatment, we proposed a drug holiday, but this drug holiday led to severe worsening of pain and nerve palsies. Therefore, this patient received this combination for 5 years (from February 2009 to
Table 3. PK parameters of imatinib

PK parameters of imatinib day 15 (monotherapy) vs day 28 (combination)

\begin{tabular}{|c|c|c|c|c|}
\hline & Day 15 & Day 28 & $\begin{array}{c}\text { Differences } \\
(\%)\end{array}$ & $\boldsymbol{P}$-value \\
\hline Mean AUC $\left(\mathrm{mghl}^{-1}\right)$ & 33.0 & 34.3 & +4.0 & 0.123 \\
\hline Mean $C_{\max }\left(\mathrm{ng} \mathrm{ml}^{-1}\right)$ & 3958.0 & 4105.0 & +2.9 & 0.145 \\
\hline Mean $C_{0}\left(\mathrm{ng} \mathrm{ml}^{-1}\right)$ & 2597.0 & 2489.0 & -12.3 & 0.334 \\
\hline Mean $T_{\max }(h)$ & 2.9 & 2.7 & -10.7 & 0.302 \\
\hline Mean $T_{1 / 2}(\mathrm{~h})$ & 14.1 & 16.4 & +3.8 & 0.267 \\
\hline
\end{tabular}

February 2013) without significant toxicity until the diagnosis of acute leukaemia. This patient is currently under treatment for this leukaemia.

We have observed clinically meaningful activity in seven chordoma patients. The median follow-up of the chordoma patients was 23.7 months. The 12-month OS rate was 6/7 and the 12 -month progression-free rate was $3 / 7$. The median PFS was not reached. Stachiotti et al (2013) have recently reported on a single-arm phase II trial of IM (800 mg per day) in 56 chordoma patients. The objective response rate was 1 of 50 (2\%). The median PFS was 9 months (Stachiotti et al, 2013). The same team had explored the activity of lapatinib (1500 mg per day) in 18 EGFRpositive chordomas. The median PFS was 8 months, with 6 confirmed partial responses (Stachiotti et al, 2013). The IM/MC combination warrants further investigation in chordoma patients.

Seventeen previously heavily treated GIST patients have been enrolled in this trial. In these cases, the PFS was 2.9 months. Growth modulation index (ratio of time to progression (TTP) with the investigational combination divided by the time to progression with the prior treatment) was available in 14 out of 17 GIST patients. The median TTP was 8.2 months (1.2-31.2) with the prior treatment and 2.7 months $(0.5-10.5)$ with the IM/MC combination. Three out of the 14 available patients (21\%) experienced a significant growth growth arrest with a growth modulation index superior to 1.33 (Von Hoff et al, 2010). These figures must be compared with the PFS observed in large retrospective study. The rechallenge of IM alone provides a median PFS of 2.9 months. The role of adding MC to rechallenge of IM in heavily pretreated patients have to be studied in an appropriate randomised trial enrolling selected cases (e.g., GIST with multiple mutations or GIST with D842V mutation).

This study demonstrates that adding MC does not interfere with the PK parameters of IM. Up until now, most trials did not document PK interaction in cases of molecularly targeted agent/ cytotoxic agent combinations (Giaccone et al, 2004; Messersmith et al, 2004; Thienelt et al, 2005; Sweeney et al, 2010; Bousquet et al, 2011; De Jonge et al, 2011; Awada et al, 2013). In a phase I trial, Hamberg et al (2010) have found that exposure to ifosfamide (another oxazaphosphorine, such as cyclophosphamide) decreased the exposure to sunitinib. In this trial, the schedule of ifosfamide was conventional $\left(6-9 \mathrm{~g} \mathrm{~m}^{-2}\right.$ per 3-4 weeks). In the present trial, the administered dose of cyclophosphamide is very low (50 mg two times daily) in comparison to the doses of cyclophosphamide that have been administered in a metronomic manner.

We have explored the safety of this association, observed some signs of activity and measured the impact of adding $\mathrm{MC}$ on 
IM PKs parameters. This combination warrants further clinical exploration in chordoma patients and, to a lesser extent, in heavily pretreated GIST patients.

\section{ACKNOWLEDGEMENTS}

We thank the patients and their families, and would also like to extend our thanks to those who provided editorial assistance. We thank the staff of their Clinical Research Unit of the Oscar Lambret Centre for the trial management and monitoring: Yvette Vendel, Muriel Chapoutier, Emilie Decoupigny, Laurence Delannoy and Sandrine Ducornet. This is an investigator-initiated trial supported financially by Novartis France.

\section{REFERENCES}

Awada A, Dirix L, Manso Sanchez L, Xu B, Luu T, Diéras V, Hershman DL, Agrapart V, Ananthakrishnan R, Staroslawska E (2013) Safety and efficacy of neratinib (HKI-272) plus vinorelbine in the treatment of patients with ErbB2-positive metastatic breast cancer pretreated with anti-HER2 therapy. Ann Oncol 24: 109-116.

Blay JY, Le Cesne A, Ray-Coquard I, Bui BN, Duffaud F, Delbaldo C, Adenis A, Viens P, Rios M, Bompas E, Cupissol D, Guillemet C, Kerbrat P, Fayette J, Chabaud S, Berthaud P, Perol D (2007) Prospective multicentric randomized phase III study of imatinib in patients with advanced gastrointestinal stromal tumors comparing interruption versus continuation of treatment beyond 1 year: the French Sarcoma Group. J Clin Oncol 25: 1107-1113.

Bouchet S, Chauzit E, Ducint D, Castaing N, Canal-Raffin M, Moore N, Titier K, Molimard M (2011) Simultaneous determination of nine tyrosine kinase inhibitors by 96 -well solid-phase extraction and ultra performance LC/ MS-MS. Clin Chim Acta 412: 1060-1067.

Bousquet G, Alexandre J, Le Tourneau C, Goldwasser F, Faivre S, de Mont-Serrat H, Kaiser R, Misset JL, Raymond E (2011) Phase I study of BIBF 1120 with docetaxel and prednisolone in metastatic chemo-naive hormone-refractory prostate cancer patients. Br J Cancer 105: 1640-1645.

De Jonge MJ, Dumez H, Kitzen JJ, Beuselinck B, Verweij J, Courtney R, Battista A, Brega N, Schöffski P (2011) Phase I safety and pharmacokinetic study of SU-014813 in combination with docetaxel in patients with advanced solid tumours. Eur J Cancer 47: 1328-1335.

Giaccone G, Gonzàlez-Larriba JL, Van Oosterom AT, Alfonso R, Smit EF, Martens M, Peters GJ, van der Vijgh WJ, Smith R, Averbuch S, Fandi A (2004) Combination therapy with gefitinib, an epidermal growth factor receptor inhibitor, gemcitabine and cisplatin in patients with advanced solid tumors. Ann Oncol 15: 831-838.

Guo J, Si L, Kong Y, Flaherty KT, Xu X, Zhu Y, Corless CL, Li L, Li H, Sheng X, Cui C, Chi Z, Li S, Han M, Mao L, Lin X, Du N, Zhang X, Li J, Wang B, Qin S (2011) Phase II, open-label, single-arm trial of imatinib mesylate in patients with metastatic melanoma harboring c-Kit mutation or amplification. J Clin Oncol 29: 2904-2909.

Hamberg P, Steeghs N, Loos WJ, Van de Biessen D, den Hollander M, Tascillar M, Verweij J, Gelderblom H, Sleijfer S (2010) Decreased exposure to sunitinib due to concomitant administration of ifosfamide: results of a phase I trial and pharmacojinctic study on the combination of sunitinib and isfosfamide in patiets with advanced solid malignancies. $\mathrm{Br} J$ Cancer 102: 1699-1706.

Messersmith WA, Laheru DA, Senzer NN, Donehower RC, Grouleff P, zRogers T, Kelley SK, Ramies DA, Lum BL, Hidalgo M (2004) Phase I trial of irinotecan, infusional 5-fluorouracil, and leucovorin (FOLFIRI) with erlotinib (OSI-774): early termination dur to increased toxicities. Clin Cancer Res 10: 6522-6527.
Penel N, Adenis A, Bocci G (2012) Cyclophosphamide-based metronomic chemotherapy: after 10 years of experience, where do we stand and where are we going? Crit Rev Oncol Hematol 82: 40-50.

Penel N, Clisant S, Dansin E, Desauw C, Degardin M, Mortier L, Vanhuyse M, Bonodeau F, Fournier C, Cazin JL, Adenis A (2010) Megestrol acetate versus metronomic cyclophosphamide in patients having exhausted all effective therapies under standard care. Br J Cancer 102: 1207-1212.

Penel N, Fournier C, Bérille J (2011b) Proposal for size justification of expanded cohort at phase-2-recommended dose. Invest New Drugs 29: 713-715.

Penel N, Le Cesne A, Bui BN, Perol D, Brain EG, Ray-Coquard I, Guillemet C, Chevreau C, Cupissol D, Chabaud S, Jimenez M, Duffaud F, Piperno-Neumann S, Mignot L, Blay JY (2011a) Imatinib for progressive and recurrent aggressive fibromatosis (desmoids tumors): an FNCLCC/ French Sarcoma Group phase II trial with a long-term follow-up. Ann Oncol 22: 452-457.

Pietras K, Hanahan D (2005) A multitargeted, metronomic, and maximumtoleated dose 'chemo-switch' regimen is antiangiogenic, producing objective responses and survival benefit in a mouse model of cancer. J Clin Oncol 23: 939-952.

Schirovi L, Nannini N, Nicoli D, Cavazza A, Valli R, Buti S, Garagnani L, Sartori G, Calabrese F, Marchetti A, Buttitta F, Felicioni L, Migaldi M, Rea F, Di Chiara F, Mengoli MC, Rossi G (2012) Activating c-Ki mutations in a subset of thymic carcinoma and reponse to different c-kit inhibitors. Ann Oncol 23: 2409-2414.

Stacchiotti S, Longhi A, Ferraresi V, Grigani G, Comandone A, Stupp R, Bertuzzi A, Tamborini E, Pilotti S, Messina A, Spreafico C, Gronchi A, Amore P, Vinaccia V, Casali PG (2012) Phase II study of imatinib in advanced chordoma. J Clin Oncol 30: 914-920.

Stachiotti S, Tamborini E, Lo Vullo S, Bozzi F, Messina A, Morosi C, Casale A, Crippa F, Conca E, Negri T, Palassini E, Marrari A, Palmerini E, Mariani L, Gronchi A, Pilotti S, Casali PG (2013) Phase II study on lapatinib in advanced EGFR-positive chordoma. Ann Oncol 24: 1931-1936.

Sweeney CJ, Chiorean EG, Verschraegen CF, Lee FC, Jones S, Royce M, Tye L, Liau KF, Bello A, Chao R, Burris HA (2010) A phase I study of sunitinib plus capecitabine in patients with advanced solid tumors. J Clin Oncol 28: 4513-4520.

Therasse P, Arbuck SG, Eisenhauer EA, Wanders J, Kaplan RS, Rubinstein L, Verweij J, Van Glabbeke M, van Oosterom AT, Christian MC, Gwyther SG (2000) New guidelines to evaluate the response to treatment in solid tumors. European Organization for Research and Treatment of Cancer, National Cancer Institute of the United States, National Cancer Institute of Canada. J Natl Cancer Inst 92: 205-216.

Thienelt CD, Bunn Jr PA, Hanna N, Rosenberg A, Needle MN, Long ME, Gustafson DL, Kelly K (2005) Multicenter phase I/II study of cetuximab with paclitaxel and caboplatin in untreated patients with stage IV nonsmall-cell lung cancer. J Clin Oncol 23: 8786-8793.

Von Hoff DD, Stephenson Jr JJ, Rosen P, Loesch DM, Borad MJ, Anthony S, Jameson G, Brown S, Cantafio N, Richards DA, Fitch TR, Wasserman E, Fernandez C, Green S, Sutherland W, Bittner M, Alarcon A, Mallery D, Penny R (2010) Pilot study using molecular profiling of patient's tumors to find potential targets and select treatments for their refractory cancers. J Clin Oncol 28: 4877-4883.

Xu Y, Wang H, Zhou S, Yu M, Wang X, Fu K, Qian Z, Zhang H, Qiu L, Liu X, Wang P (2013) Risk of second malignant neoplasms after cyclophosphamide-based chemotherapy with or without radiotherapy for non-Hodgkin lymphoma. Leuk Lymphoma 54: 1396-1404.

This work is published under the standard license to publish agreement. After 12 months the work will become freely available and the license terms will switch to a Creative Commons AttributionNonCommercial-Share Alike 3.0 Unported License. 